CLINICAL STUDY

\title{
Metabolic and cardiovascular outcomes in a group of adult patients with Turner's syndrome under hormonal replacement therapy
}

\author{
Roberta Giordano $^{1}$, Daniela Forno ${ }^{1}$, Fabio Lanfranco ${ }^{2}$, Chiara Manieri ${ }^{2}$, Lucia Ghizzoni ${ }^{2}$ and Ezio Ghigo ${ }^{2}$ \\ ${ }^{1}$ Department of Clinical and Biological Sciences and ${ }^{2}$ Division of Endocrinology, Diabetology and Metabolism, Department of Internal Medicine, University \\ of Turin, Ospedale San Giovanni Battista-Molinette, C.so Dogliotti 14, 10126 Turin, Italy \\ (Correspondence should be addressed to E Ghigo; Email: ezio.ghigo@unito.it)
}

\begin{abstract}
Objective: Turner's syndrome (TS) is a rare genetic disorder caused by complete or partial X chromosome monosomy in a phenotypic female, and it is associated with increased morbidity and mortality for cardiovascular diseases, impaired glucose tolerance, and dyslipidemia.

Subjects and methods: In 30 adult TS patients under chronic hormonal replacement therapy (HRT), $17 \beta$-estradiol $\left(\mathrm{E}_{2}\right)$, body mass index $(\mathrm{BMI})$, waist circumference, fasting glucose and insulin, homeostatic model assessment (HOMA) index, serum lipids, oral glucose tolerance test (OGTT), $24 \mathrm{~h}$ ambulatory blood pressure monitoring (ABPM), and intima-media thickness (IMT) were evaluated and compared with those in 30 age- and sex-matched controls (CS).

Results: No difference was found between TS and CS in $\mathrm{E}_{2}$ and BMI, whereas waist circumference was higher $(P<0.05)$ in TS $(77.7 \pm 2.5 \mathrm{~cm})$ than in CS $(69.8 \pm 1.0 \mathrm{~cm})$. Fasting glucose in TS and in CS was similar, whereas fasting insulin, HOMA index, and $2 \mathrm{~h}$ glucose after OGTT were higher $(P<0.0005)$ in TS $(13.2 \pm 0.8 \mathrm{mUI} / \mathrm{l}, 2.5 \pm 0.2$, and $108.9 \pm 5.5 \mathrm{mg} / \mathrm{dl}$ respectively $)$ than in CS $(9.1 \pm 0.5 \mathrm{mUI} / \mathrm{l}, 1.8 \pm 0.1$, and $94.5 \pm 3.8 \mathrm{mg} / \mathrm{dl}$ respectively $)$. Total cholesterol was higher $(P<0.05)$ in TS $(199.4 \pm 6.6 \mathrm{mg} / \mathrm{dl})$ than in CS $(173.9 \pm 4.6 \mathrm{mg} / \mathrm{dl})$, whereas no significant differences in highdensity lipoprotein, low-density lipoprotein, and triglycerides were found between the two groups. In $13 \%$ of TS, ABPM showed arterial hypertension, whereas IMT was $<0.9 \mathrm{~mm}$ in all TS and CS. A negative correlation between insulin levels, HOMA index, or $2 \mathrm{~h}$ glucose after OGTT and $\mathrm{E}_{2}$ was present in TS.

Conclusions: Our results indicate that adult patients with TS under HRT are connoted by higher frequency of central obesity, insulin resistance, hypercholesterolemia, and hypertension.

European Journal of Endocrinology 164 819-826
\end{abstract}

\section{Introduction}

Turner's syndrome (TS), a rare congenital disease affecting about one in every 2500-3000 live-born females, is the result of chromosomal abnormalities in a phenotypic female, associated with characteristic clinical features, the most consistent being short stature, ovarian failure, and specific somatic abnormalities (1). Complete 45,X monosomy accounts for $40-60 \%$ of the karyotypes, whereas $5-10 \%$ of patients have a duplication of the long arm of one $\mathrm{X}$ (isochromosome $\mathrm{Xq}$ ) and most of the remaining karyotypes show a mosaicism (1). A correlation between karyotype and phenotype has been reported, as the presence of an isochromosome Xq coupled with an increased risk for diabetes mellitus, hypothyroidism, and inflammatory bowel disease (1).

Subjects with TS usually receive intensive medical care during childhood, but the majority are discharged from specialist clinics after the induction of puberty and attainment of final height. Since the description of TS by Henry H Turner in 1938 (2), a wealth of information has been added and our current understanding of the syndrome is continuously being broadened. It has long been known that left-sided congenital cardiac abnormalities are more prevalent in women with TS, and recent studies have demonstrated that these women have a threefold increase in mortality, primarily as a results of cardiovascular complications (3-6), and several risk factors for ischemic heart disease including hypertension $(4,7)$, insulin resistance $(8-10)$, and hyperlipidemia $(10,11)$.

By contrast with the intensive medical follow-up in childhood, follow-up is often grossly inadequate in adult patients with TS, although early medical intervention may reduce morbidity and improve life expectancy, as pointed out by The Turner Syndrome Consensus Study Group in 2007 (12). 
In spite of the negative results of Heart and Estrogen/progestin Replacement (HERS (13)) and Women's Healthy Initiative (WHI (14)) studies, over the past 20 years, numerous observational, retrospective, interventional, and meta-analytic studies as well as studies using animal models have supported the hypothesis that hormonal replacement therapy (HRT) exerts important beneficial effects on heart disease, diabetes and obesity. The mechanisms are not completely understood but include a favorable effect on lipids and insulin sensitivity as well as beneficial effects on endothelial and vascular smooth muscle function (15). As HRT was shown to only partially normalize some metabolic alterations in TS (10), it was hypothesized that the X chromosome deletion per se, apart from the effects of estrogen deficiency, might be causally related to the metabolic impairment in this syndrome.

Based on this background, we designed a clinical study aimed at evaluating the metabolic and cardiovascular profile in a group of adult patients with TS under chronic HRT, in comparison with a group of ageand sex-matched normal healthy subjects.

\section{Subjects and methods}

We studied 30 patients with TS (age, mean \pm s.E.M.: $32.4 \pm 1.3$ years) of Caucasian origin.

The diagnosis of TS was based on peripheral leukocyte karyotype analysis and the following karyotypes were identified: 45,X $(n=18) ; 45, \mathrm{X} / 46, \mathrm{XX}$ $(n=4) ; 45, \mathrm{X} / 46, \mathrm{XY}(n=1) ; 46, \mathrm{X}, \mathrm{i}(\mathrm{Xq})$ or $45, \mathrm{X} / 46, \mathrm{X}, \mathrm{i}$ (Xq) $(n=3) ; 45, X / 46, X r(n=2)$; and $46, X X p-$ or $46, \mathrm{XXq}-(n=2)$.

In all the $45, X$ patients, the diagnosis was made at birth or in early childhood for the presence of characteristic clinical features; in two patients with 45,X/46,XX mosaicism, the diagnosis was made for secondary amenorrhea and short stature during adulthood, whereas in the remaining patients, the diagnosis was made during mid-childhood for short stature or at pubertal age for primary amenorrhea.

All the patients were under HRT with oral or transdermal $17 \beta$-estradiol $\left(\mathrm{E}_{2}, 2 \mathrm{mg}\right.$ daily or $100 \mu \mathrm{g} / 24 \mathrm{~h}$ in 25 patients and $1 \mathrm{mg}$ daily or $50 \mu \mathrm{g} / 24 \mathrm{~h}$ in the remaining five patients), in association with oral synthetic progestagen (dydrogesterone $10 \mathrm{mg}$ in 10 patients, nomegestrol acetate $5 \mathrm{mg}$ or medroxyprogesterone acetate $10 \mathrm{mg}$ in the remaining 20 patients), for a mean period of 18 years (range, 7-32 years). They were all studied during the estrogen phase of treatment, on days 5-10.

None of the patients was receiving any drug influencing blood pressure, glucose, or lipid metabolism at the time of the study; all patients were non-smokers, and none had familial history of cardiovascular disease.

Among the patients enrolled in the study, five patients were affected by congenital cardiovascular disease (two with coarctation of aorta, two with bicuspid aortic valve, and one with mitral valve prolapse) but normal ventricular function, ten patients by autoimmune hypothyroidism under appropriate treatment with L-thyroxin at the time of the study (leading to normal circulating TSH, free tri-iodothyronine, and free thyroxine levels), and two patients by celiac disease under gluten-free diet at the time of the study. Moreover, 20 patients had short stature that had been treated with rhGH during childhood; they showed normal IGF1 levels as well as a normal GH response to ARG + GHRH test at the time of the study.

The main genetic, anthropometric, clinical, and hormonal findings of the patients are reported in Table 1.

In this study, 30 age-matched women were enrolled as control group (CS) and were evaluated in their early follicular phase. The control group was matched with respect to age but not to body mass index (BMI), as TS patients have been reported to have a higher waist circumference than normal women given the same BMI (16). None of the controls were taking medications known to interfere with glucose or lipid metabolism or influence blood pressure; all controls were non-smokers, and none had familial or personal history of cardiovascular disease.

All the patients and the controls gave their informed consent to participate in the study, which had been approved by the ethical committee of the University of Turin, in agreement with the Declaration of Helsinki.

\section{Clinical evaluation}

Weight, height, BMI, and waist circumference were measured using standard methods. A BMI between 25 and $29.9 \mathrm{~kg} / \mathrm{m}^{2}$ was classified as overweight and a BMI of $30 \mathrm{~kg} / \mathrm{m}^{2}$ or more as obesity (17); a waist circumference $>88 \mathrm{~cm}$ was used to define abdominal adiposity (17).

\section{Biochemical evaluation}

Fasting blood samples were drawn in the morning, between 0800 and $0900 \mathrm{~h}$, from all patients and from all controls.

$\mathrm{E}_{2}$, glucose, insulin, total cholesterol, high-density lipoprotein (HDL) cholesterol, and triglyceride levels were measured in duplicate by different assays as detailed in Table 2, whereas HOMA index and low-density lipoprotein (LDL) cholesterol were calculated as follows: fasting insulin $(\mathrm{mU} / \mathrm{l}) \times$ fasting glucose $(\mathrm{mmol} / \mathrm{l}) / 22.5$ and total cholesterol - (HDL + (triglycerides/5) respectively. An oral glucose tolerance test (OGTT, 75 g glucose, measuring blood glucose concentrations at $0^{\prime}$ and $120^{\prime}$ ) was also performed.

According to ADA criteria, impaired fasting glucose (IFG) was defined as glucose levels $\geq 100 \mathrm{mg} / \mathrm{dl}$ $(5.6 \mathrm{mmol} / \mathrm{l})$, whereas impaired glucose tolerance (IGT) was diagnosed when $2 \mathrm{~h}$ glucose levels after OGTT were between $140(7.8 \mathrm{mmol} / \mathrm{l})$ and $200 \mathrm{mg} / \mathrm{dl}$ (11.1 mmo/l) (17). 


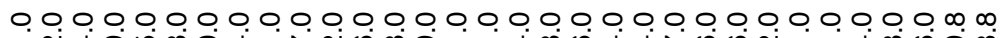

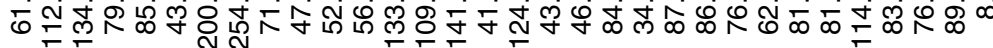

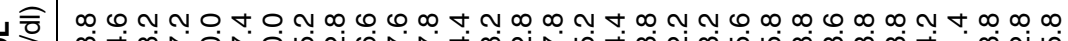

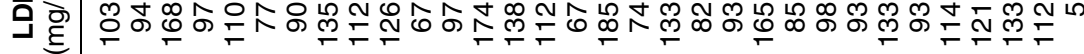

के 00000000000000000000000000000000 이 Љ

O 00000000000000000000000000000000 ๙ँ 1

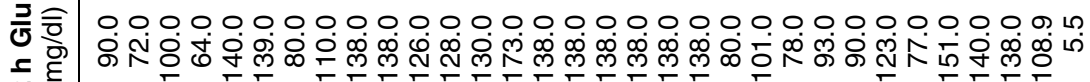
๓ m

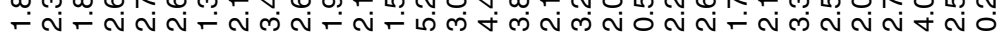

omotto o o on

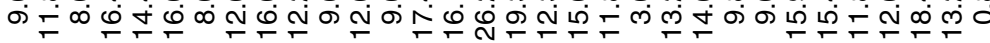

$000000000000000000000000000000 \mathrm{~N}$ 는 ๓

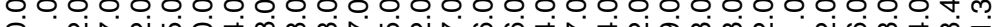

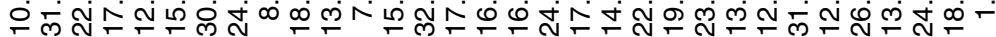

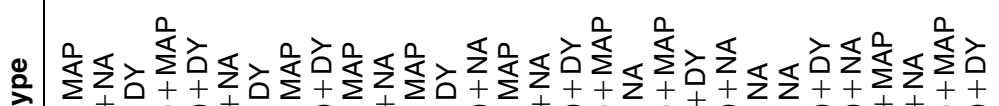

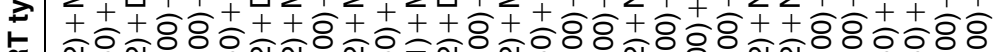

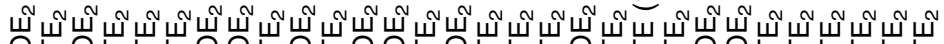

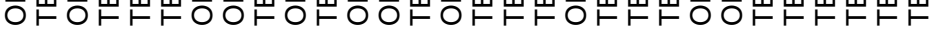

$00001000000000 \mathrm{Nam} 000000-000+000 \mathrm{~m}$

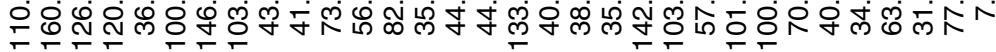

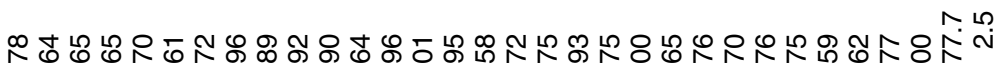

0 0 0 0 m

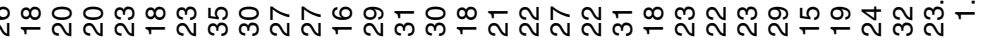
나

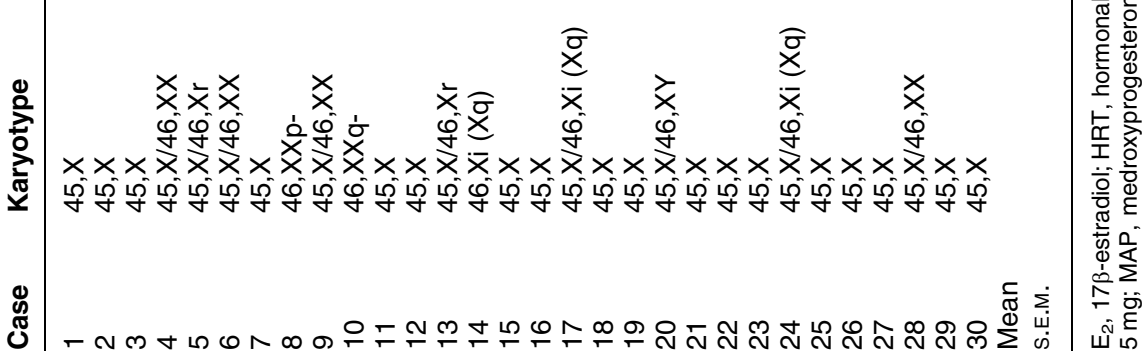


Table 2 Biochemical details of parameters assayed.

\begin{tabular}{|c|c|c|c|c|c|}
\hline \multirow[b]{2}{*}{ Parameter } & \multirow[b]{2}{*}{ Units (SI) } & \multirow[b]{2}{*}{ Method } & \multirow[b]{2}{*}{ Sensitivity } & \multicolumn{2}{|c|}{ Coefficients of variation (\%) } \\
\hline & & & & Inter-assay & Intra-assay \\
\hline $17 \beta$-Estradiol & $\mathrm{pg} / \mathrm{ml}(\mathrm{pg} / \mathrm{ml} \times 3.671=\mathrm{pmol} / \mathrm{l})$ & $\begin{array}{l}\text { RIA (Ultra sensitive RIA DSL-4800, } \\
\text { Pantect S.r.I, Italy) }\end{array}$ & $2.2 \mathrm{pg} / \mathrm{ml}$ & $7.5-12.2$ & $6.5-8.9$ \\
\hline Glucose & $\mathrm{mg} / \mathrm{dl}(\mathrm{mg} / \mathrm{dl} \times 0.0555=\mathrm{mmol} / \mathrm{l})$ & $\begin{array}{l}\text { Colorimetric method } \\
\text { (Roche Diagnostic } \mathrm{GmbH})\end{array}$ & $2 \mathrm{mg} / \mathrm{dl}$ & $1.7-1.9$ & $0.8-1.1$ \\
\hline Insulin & $\mathrm{mIU} / \mathrm{l}(\mathrm{mIU} / \mathrm{l} \times 7.175=\mathrm{pmol} / \mathrm{l})$ & $\begin{array}{l}\text { IRMA (INSIK-5, SORIN Biomedica, } \\
\text { Saluggia, Italy) }\end{array}$ & $2.5 \mathrm{mUl} / \mathrm{l}$ & $6.2-10.8$ & $5.5-10.6$ \\
\hline Total cholesterol & $\mathrm{mg} / \mathrm{dl}(\mathrm{mg} / \mathrm{dl} \times 0.025=\mathrm{mmol} / \mathrm{l})$ & $\begin{array}{l}\text { Enzymatic colorimetric method } \\
\text { (Roche Diagnostic } \mathrm{GmbH})\end{array}$ & $3 \mathrm{mg} / \mathrm{dl}$ & $1.7-2.7$ & $0.7-1$ \\
\hline HDL-cholesterol & $\mathrm{mg} / \mathrm{dl}(\mathrm{mg} / \mathrm{dl} \times 0.025=\mathrm{mmol} / \mathrm{l})$ & $\begin{array}{l}\text { Enzymatic colorimetric method } \\
\text { (Roche Diagnostic } \mathrm{GmbH})\end{array}$ & $3 \mathrm{mg} / \mathrm{dl}$ & $1.1-1.8$ & $0.6-0.9$ \\
\hline Triglycerides & $\mathrm{mg} / \mathrm{dl}(\mathrm{mg} / \mathrm{dl} \times 0.011=\mathrm{mmol} / \mathrm{l})$ & $\begin{array}{l}\text { Enzymatic colorimetric method } \\
\text { (Roche Diagnostic } \mathrm{GmbH} \text { ) }\end{array}$ & $4 \mathrm{mg} / \mathrm{dl}$ & $1.8-2.4$ & $0.9-1.5$ \\
\hline
\end{tabular}

Hypertriglyceridemia was diagnosed when triglycerides were above $150 \mathrm{mg} / \mathrm{dl}(1.7 \mathrm{mmol} / \mathrm{l})$, whereas hypercholesterolemia was diagnosed when total cholesterol levels were above $240 \mathrm{mg} / \mathrm{dl}(6.2 \mathrm{mmol} / \mathrm{l})(17)$.

\section{Blood pressure and vascular evaluation}

All the patients and controls underwent standard 12 lead electrocardiogram (ECG), $24 \mathrm{~h}$ ambulatory blood pressure monitoring (ABPM TM 2430, A\&D Instrument by Intermed; Veris Srl, Italy), and echo color Doppler ultrasonography (Technos MPX Esaote; Genoa, Italy) for intima-media thickness (IMT). The $24 \mathrm{~h} \mathrm{ABPM}$ was measured using an oscillometric method obtaining readings every $15^{\prime}$ during the daytime and $20^{\prime}$ during the nighttime; the monitoring started the same morning when blood samples were drawn, between 0800 and $0900 \mathrm{~h}$, and ended the following morning at the same time. IMT was measured at right and left carotid arteries that were scanned longitudinally, about $1 \mathrm{~cm}$ before carotid bulbs; each measure was repeated at least three times and the mean was taken into consideration.

A $24 \mathrm{~h}$ mean systolic blood pressure below $125 \mathrm{mmHg}$ and a $24 \mathrm{~h}$ mean diastolic blood pressure below $80 \mathrm{mmHg}$ were considered normal accordingly to PAMELA Study (18). According to the European Society of Hypertension and European Society of Cardiology 2007 Guidelines for the Management of Arterial Hypertension, an IMT $<0.9 \mathrm{~mm}$ was considered normal (19).

\section{Statistical analysis}

Results are expressed as mean \pm s.E.M. The statistical analysis was carried out using the Mann-Whitney $U$ test for comparison between patients and controls. Correlations between $\mathrm{E}_{2}$ levels or age, BMI, waist and fasting glucose, insulin, $2 \mathrm{~h}$ glucose after OGTT, and serum lipids were carried out using the Spearman correlation coefficient. Multiple linear regression analysis among the above-mentioned variables was then performed. Statistical significance was set at $P<0.05$. Statistical Package for the Social Science (SPSS 17.0 for Windows: SPSS, Inc., 1989-2005, Chicago, IL, USA) was used for the analysis (20).

\section{Results}

No difference was found between TS and CS in $\mathrm{E}_{2}$ (mean \pm s.E.M.: $77.0 \pm 7.3 \mathrm{vs} 80.7 \pm 6.0 \mathrm{pg} / \mathrm{ml}$ ) and BMI $\left(23.9 \pm 1.0\right.$ vs $\left.22.8 \pm 0.5 \mathrm{~kg} / \mathrm{m}^{2}\right)$, whereas waist was higher $(P<0.05)$ in TS $(77.7 \pm 2.5 \mathrm{~cm})$ than in CS $(69.8 \pm 1.0 \mathrm{~cm})$; considering individual cases, central obesity was present in five TS (17\%) and in none of the CS (Table 1 and Figs 1 and 2).

Mean fasting glucose was similar in TS (77.5 $\pm 2.2 \mathrm{mg} / \mathrm{dl})$ and in CS $(80.4 \pm 1.5 \mathrm{mg} / \mathrm{dl})$, whereas

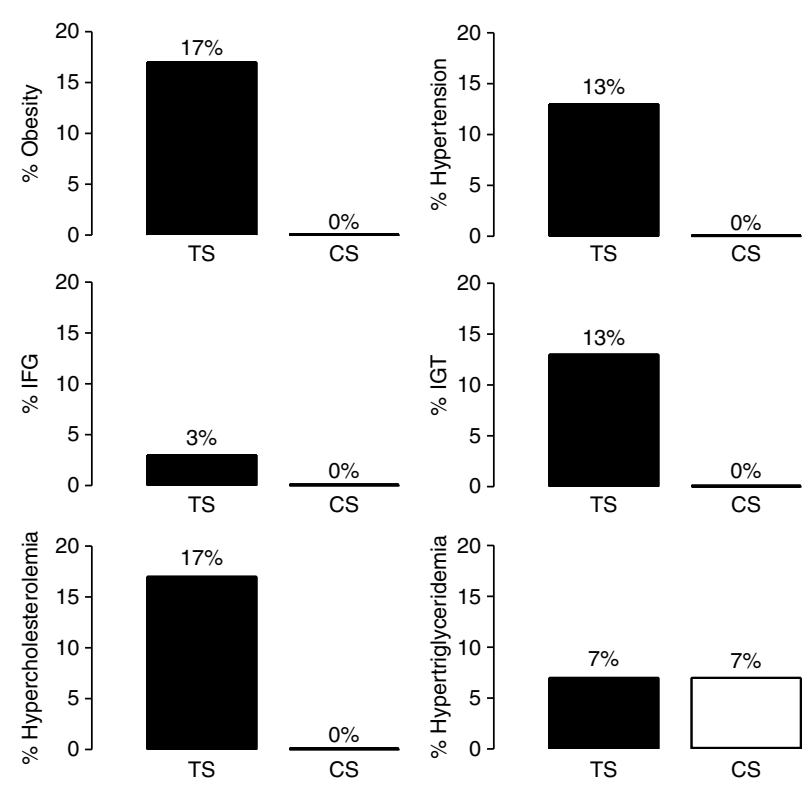

Figure 1 Percentage of patients with Turner's syndrome (filled bar) and control subjects (open bar) with obesity, hypertension, IFG, IGT, hypercholesterolemia, and hypertriglyceridemia. 


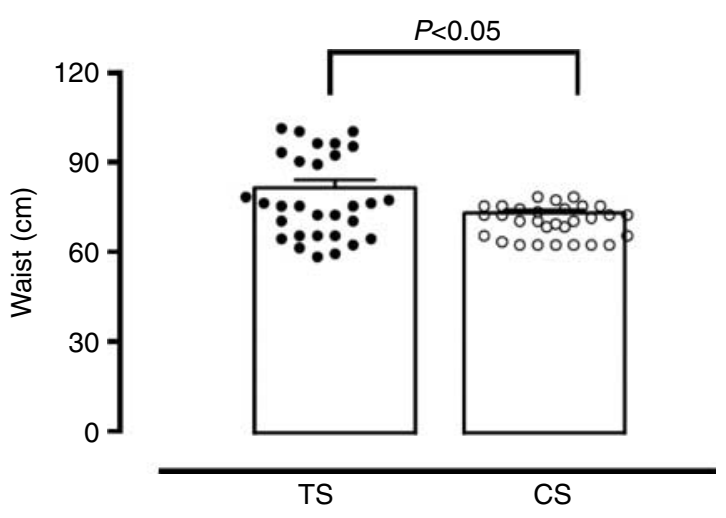

Figure 2 (Mean \pm S.E.M.) and individual waist in patients with Turner's syndrome (filled circle) and control subjects (open circle).

fasting insulin, HOMA index, and $2 \mathrm{~h}$ glucose after OGTT were higher $(P<0.0005)$ in TS $(13.2 \pm 0.8 \mathrm{mIU} / \mathrm{l}$, $2.5 \pm 0.2$, and $108.9 \pm 5.5 \mathrm{mg} / \mathrm{dl}$ respectively) than in CS $(9.1 \pm 0.5 \mathrm{mIU} / \mathrm{l}, 1.8 \pm 0.1$, and $94.5 \pm 3.8 \mathrm{mg} / \mathrm{dl}$ respectively). Specifically, one TS (3\%) and none of the CS were IFG, whereas four TS (13\%) and none of the CS were IGT; none of the TS or CS was affected by diabetes mellitus (Table 1 and Figs 1 and 3).

Total cholesterol was higher $(P<0.05)$ in TS $(199.4 \pm 6.6 \mathrm{mg} / \mathrm{dl})$ than in CS $(173.9 \pm 4.6 \mathrm{mg} / \mathrm{dl})$, whereas no significant differences in HDL-cholesterol $(68.6 \pm 2.9$ vs $58.9 \pm 1.7 \mathrm{mg} / \mathrm{dl})$, LDL-cholesterol $(112.8 \pm 5.8$ vs $96.4 \pm 4.1 \mathrm{mg} / \mathrm{dl})$, or triglycerides $(89.8 \pm 8.8$ vs $90.3 \pm 6.6 \mathrm{mg} / \mathrm{dl})$ were detected. Considering individual cases, total cholesterol was $>240 \mathrm{mg} / \mathrm{dl}$ in five TS (17\%), LDL-cholesterol was $>160 \mathrm{mg} / \mathrm{dl}$ in three TS $(10 \%)$, whereas no TS or CS showed either HDL $<40 \mathrm{mg} / \mathrm{dl}$ or LDL-cholesterol $>190 \mathrm{mg} / \mathrm{dl}$. Triglycerides were $>150 \mathrm{mg} / \mathrm{dl}$ in two TS and two CS (7\%) respectively (Table 1 and Figs 1 and 4 ).

In all CS, $24 \mathrm{~h}$ blood pressure monitoring showed a normal profile with preserved circadian variation, whereas a loss of nocturnal reduction in blood pressure and a diagnosis of arterial hypertension were made in four TS (13\%), independent of HRT type or karyotype; in none of the hypertensive patients, renal or cardiac diseases were present (Fig. 1).

No significant difference in the metabolic parameters were found between TS under standard dose $E_{2}$ treatment and low-dose $\mathrm{E}_{2}$ treatment (data not shown).

IMT was $<0.9 \mathrm{~mm}$ in all TS and CS, and no ECG abnormalities were found in either TS or CS (data not shown).

\section{Correlation analysis}

In TS, but not in CS, the $\mathrm{E}_{2}$ levels negatively correlated with fasting insulin $(r=-0.41 ; P=0.02)$, HOMA index $(r=-0.44 ; P=0.01)$, and $2 \mathrm{~h}$ glucose after OGTT $(r=-0.66 ; P<0.0001)$, whereas total cholesterol and HDL-cholesterol positively correlated with waist circumference ( $r=0.45$ and $0.40 ; P=0.01$ and 0.02 ).

In TS, at the multiple regression analysis, $E_{2}$ remained the best predictor of fasting insulin $(\beta=$ $-0.53, P=0.005)$, HOMA index $(\beta=-0.53$, $P=0.006)$, and $2 \mathrm{~h}$ glucose after OGTT $(\beta=-0.64$, $P=0.0001)$, whereas waist circumference was the best predictor of HDL-cholesterol $(\beta=1.43, P=0.003)$.

In TS, no significant correlations between BMI, waist or the glucolipids parameters, and karyotypes or $\mathrm{E}_{2}$-treatment duration were found.

\section{Discussion}

The results of our present study show that patients with TS are characterized by a higher prevalence of central obesity, IGT, hypercholesterolemia, and hypertension, when compared with age- and sex-matched normal subjects, even under chronic HRT.

Central obesity was present in a higher percentage of patients than controls; however, no correlation between BMI or waist circumference and estrogen levels was detected in our patients, thus suggesting a lacking influence of estrogens on these anthropometric parameters. In our study, the control group was not matched with respect to BMI, as TS patients have been reported to have a higher waist circumference than normal women given the same BMI (16), and therefore such a matching would have been misleading. These data are at variance from those of the previous studies indicating a direct correlation between gonadal status and visceral adiposity, with TS at diagnosis having a higher waist than normal women with similar BMI $(16,21)$. On the other hand, these results do not support either the evidence that HRT is able to improve fat-free mass and waist-hip ratio in women with TS as
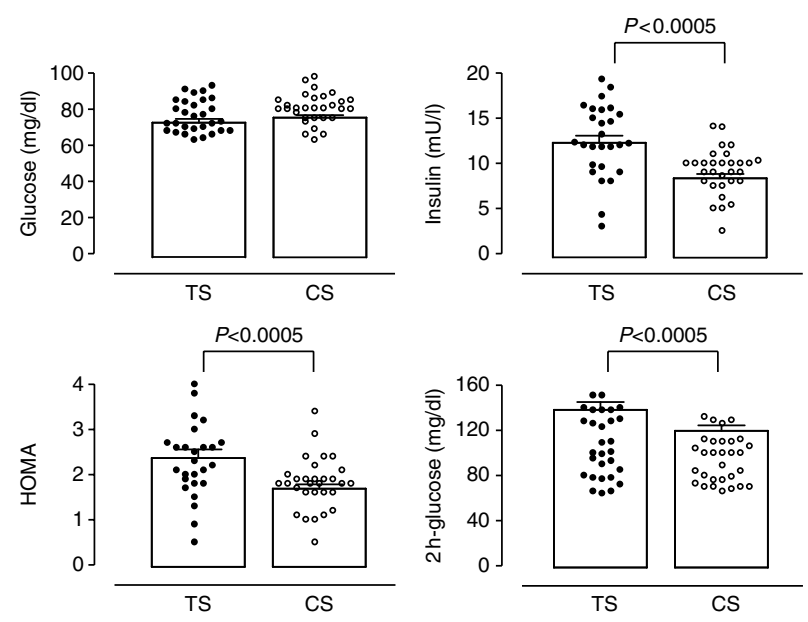

Figure 3 (Mean \pm S.E.M.) and individual fasting glucose, insulin, HOMA, and $2 \mathrm{~h}$ glucose after OGTT ( $2 \mathrm{~h} \mathrm{Glu}$ ) in patients with Turner's syndrome (filled circle) and control subjects (open circle). 

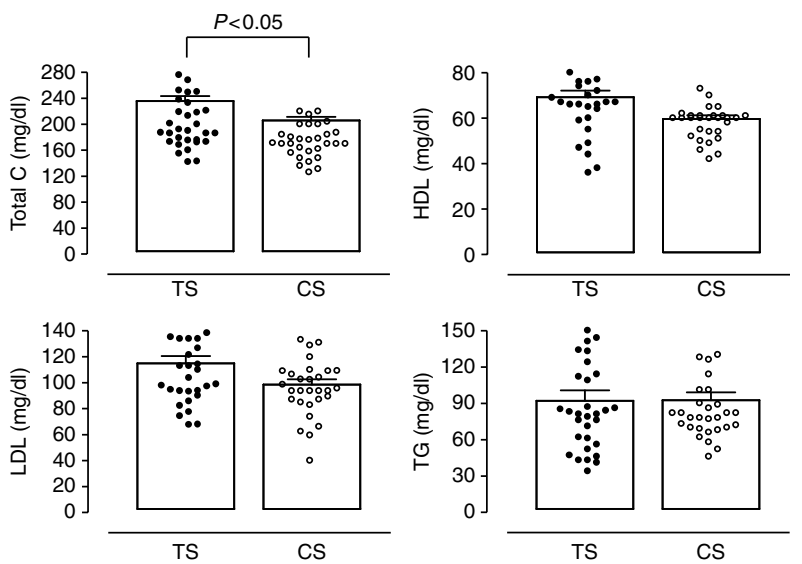

Figure 4 (Mean \pm S.E.M.) and individual total cholesterol (Total C), HDL-cholesterol (HDL), LDL-cholesterol (LDL), and triglycerides (TG) in patients with Turner's syndrome (filled circle) and control subjects (open circle).

reported by some authors (21) or the role of HRT in preventing abdominal fat accumulation in post-menopausal women (22). Unfortunately, we did not perform a body composition evaluation that would have better differentiated patients from controls and better characterized TS adult women.

In agreement with other studies (8-10), we found an impaired insulin sensitivity, in term of higher HOMA index and abnormal glucose response to OGTT, in a higher percentage of patients than controls. The lack of any correlation between BMI or waist circumference and glucose tolerance is in agreement with the previous studies that demonstrated a higher frequency of type 2 diabetes mellitus and IGT in women with TS than in normal women, independent of BMI (4). Interestingly, the existence of a negative correlation between these glycemic parameters and circulating $\mathrm{E}_{2}$ levels in our patients confirms the possible role of $\mathrm{E}_{2}$ in the derangement of glucose metabolism and insulin sensitivity, as previously reported in TS $(10,23)$ and in normal post-menopausal women with diabetes mellitus (24), although circulating $\mathrm{E}_{2}$ levels alone do not reflect the adequacy of HRT in the absence of adjunctive clinical evaluation. At present, data concerning the effects of estrogens on glucose metabolism and insulin sensitivity in humans are conflicting. In particular, short-term supraphysiological estrogen administration possesses an adverse effect on glucose tolerance, resulting from the suppression of first-phase insulin secretion and increased insulin, whereas the main longterm effect of estrogens is preservation of the pancreatic insulin responses to glucose (25). Despite the limitations of using OGTT-derived parameters to evaluate insulin sensitivity, our findings strongly support the concept of an insulin resistance state as the main mechanism of Turner diabetogenic phenotype that was not completely normalized by HRT.
As far as the lipid profile is concerned, we found a higher prevalence of hypercholesterolemia in patients than in controls, although no significant differences between the two groups were found for LDL- and HDL-cholesterol. However, none of the patients showed LDL-cholesterol $>190 \mathrm{mg} / \mathrm{dl}$, the cutoff level for pharmacological intervention, and $10 \%$ of them displayed LDL-cholesterol $>160 \mathrm{mg} / \mathrm{dl}$, the cutoff level for lifestyle intervention (17). The absence of correlation between lipid profile and $\mathrm{E}_{2}$ levels recorded in our study suggests that the influence of $E_{2}$ in the development of hypercholesterolemia in TS is minor, whereas the positive correlation between lipids and waist circumference implies that central obesity may be involved in the derangement of the lipid profile in this disease. Our findings are in reference with those of the other authors' findings who have reported high cholesterol levels in untreated TS, independent of BMI and karyotype (26). On the other hand, other investigators have not confirmed that in TS, cholesterol values differ from those of normal women (10), whereas a higher prevalence of hypertriglyceridemia in TS was reported in other studies $(11,27)$. Our results do not support a possible role of HRT in the improvement of lipid profile, as reported in post-menopausal women (28-31), but this is not surprising given the different clinical and hormonal conditions of TS patients that makes the comparison with post-menopausal normal women inappropriate. Randomized controlled trials in larger group of patients are required to definitively assess the effect of HRT on lipid profile in females with TS.

In agreement with other reports, we showed a higher prevalence of hypertension in our patients, although lower than that estimated by epidemiological studies (7). Furthermore, the $24 \mathrm{~h}$ ambulatory blood pressure monitoring revealed a loss of nocturnal reduction in blood pressure suggestive of a diagnosis of arterial hypertension in patients otherwise considered normotensive by single ambulatory blood pressure evaluation. The exact mechanism of hypertension in TS has not been clearly identified: an increase in plasma renin activity has been found in $50 \%$ of cases by some authors and abnormal vagosympathetic tone, explaining relative tachycardia, has recently been described (7). As hypertension is an important risk factor for cardiovascular complications, it is important that TS patients undergo $24 \mathrm{~h}$ ambulatory blood pressure monitoring to detect the presence of hypertension that would be missed by a single blood pressure measurement. The lack of effect of HRT on blood pressure is consistent with some studies in women with TS (10) as well as in post-menopausal women (32), whereas other authors reported a reduced diastolic blood pressure during HRT in TS (33).

As increased IMT is considered a precursor of clinically detectable atherosclerosis and is associated with higher cardiovascular risk (34), we also evaluated this parameter in our patients, compared with controls, 
and were unable to detect any abnormality; this result agrees with that of other studies in women with TS that reported no effect of HRT on ambulatory arterial stiffness index (33), although it opposes previous trials showing beneficial effects of HRT on IMT in comparably aged TS women (35).

The absence of correlation between IMT and $E_{2}$ in TS seems, once again, to make a significant role of estrogen in the development of human atherosclerosis and endothelial dysfunction in adult TS unlikely. Our results are in contrast with other studies in TS and postmenopausal women, where IMT has been reported to be high at diagnosis and normalized by estrogen treatment (32, 35-39). A possible explanation for these contradictory results may be a differential effect of estrogens at different stages of the atherosclerotic disease process, with beneficial anti-atherogenic effects earlier in life but pro-inflammatory and pro-thrombotic effects predominating in the older, post-menopausal age group.

As central adiposity together with insulin resistance and hyperlipidemia are well-recognized risk factors for cardiovascular disease, our overall results confirm that adult patients with TS had a more harmful metabolic and cardiovascular profile than healthy women, independent of the karyotype.

Considering that the management of adult patients with TS is a critical issue of debate, the results of our study, together with those of the previous studies, indicate that an evaluation of cardiovascular risk factors and optimal hormonal replacement is mandatory in this rare syndrome.

Our study suffers from some limitations: first, the small number of patients, as well as their heterogeneity, did not allow us to draw definitive conclusions on morbidity; secondly, we were unable to correlate the type of karyotype or HRT with the metabolic/cardiovascular profile, as we included different karyotypes and therapeutic regimens; thirdly, the absence of comparative cohort group of patients without HRT did not allow us to draw definitive conclusions on the role of HRT in metabolic and cardiovascular impairment of TS.

In conclusion, our results indicate that adult patients with TS under HRT are characterized by a higher frequency of central obesity, insulin resistance, hypercholesterolemia, and hypertension, suggesting an increased cardiovascular risk. Whether the cardiovascular risk is intrinsic to the disease or related to the HRT deserves further investigation.

\section{Declaration of interest}

The authors declare that there is no conflict of interest that could be perceived as prejudicing the impartiality of the research reported.

\section{Funding}

This study was supported by the University of Turin and Foundation for the Study of Metabolic and Endocrine Diseases (SMEM).

\section{Acknowledgements}

The authors wish to thank Dr A Bertagna and Dr G Mengozzi for their skillful technical assistance.

\section{References}

1 Gravholt $\mathrm{CH}$. Epidemiological, endocrine and metabolic features in Turner syndrome. European Journal of Endocrinology 2004151 657-687. (doi:10.1530/eje.0.1510657)

2 Turner HH. A syndrome of infantilism, congenital webbed neck and cubitus valgus. Endocrinology $1938 \quad 23 \quad 566-574$. (doi:10.1210/endo-23-5-566)

3 Price WH, Clayton JF \& Collyer S. Mortality ratios, life expectancy, and causes of death in patients with Turner's syndrome. Journal of Epidemiology and Community Health 198640 97-102. (doi:10.1136/jech.40.2.97)

4 Gravholt CH, Juul S \& Naeraa RW. Morbidity in Turner syndrome. Journal of Clinical Epidemiology 199851 147-158. (doi:10.1016/ S0895-4356(97)00237-0)

5 Stochholm K, Juul S \& Juel K. Prevalence, incidence, diagnostic delay, and mortality in Turner syndrome. Journal of Clinical Endocrinology and Metabolism 200691 3897-3902. (doi:10. 1210/jc.2006-0558)

6 Schoemaker MJ, Swerdlow AJ \& Higgins CD. Mortality in women with Turner syndrome in Great Britain: a national cohort study. Journal of Clinical Endocrinology and Metabolism 200893 4735-4742. (doi:10.1210/jc.2008-1049)

7 Nathwani NC, Unwin R \& Brook CG. Blood pressure and Turner syndrome. Clinical Endocrinology 200052 363-370. (doi:10. 1046/j.1365-2265.2000.00960.x)

8 Stoppoloni G, Prisco F \& Alfano C. Characteristics of insulin resistance in Turner syndrome. Diabetes and Metabolism 199016 267-271.

9 Caprio S, Boulware S \& Diamond M. Insulin resistance: an early metabolic defect of Turner's syndrome. Journal of Clinical Endocrinology and Metabolism 199172 832-836. (doi:10.1210/ jcem-72-4-832)

10 Gravholt CH, Naeraa RW \& Nyholm B. Glucose metabolism, lipid metabolism, and cardiovascular risk factors in adult Turner syndrome: the impact of sex hormone replacement. Diabetes Care 199821 1062-1070. (doi:10.2337/diacare.21.7.1062)

11 Van PL, Bakalov VK \& Bondy CA. Monosomy for the $\mathrm{X}$-chromosome is associated with an atherogenic lipid profile. Journal of Clinical Endocrinology and Metabolism 200691 2867-2870. (doi:10.1210/jc.2006-0503)

12 Bondy CA. Care of girls and women with Turner syndrome: A Guideline of the Turner Syndrome Study Group. Journal of Clinical Endocrinology and Metabolism 200792 10-25. (doi:10.1210/jc. 2006-1374)

13 Hulley S, Grady D \& Bush T. Randomized trial of estrogen plus progestin for secondary prevention of coronary heart disease in postmenopausal women. Heart and Estrogen/progestin Replacement Study (HERS) Research Group. Journal of the American Medical Association 1998280 605-613. (doi:10.1001/jama.280.7.605)

14 Writing Group for the Women's Health Initiative Investigators. Risks and benefits of estrogen plus progestin in healthy postmenopausal women: principal results from the Women's Health Initiative randomized controlled trial. Journal of the American Medical Association 2002288 321-333. (doi:10.1001/jama.288.3.321)

15 Turgeon JL, Carr MC \& Maki PM. Complex actions of sex steroids in adipose tissue, the cardiovascular system, and brain: insights from basic science and clinical studies. Endocrine Reviews 200627 575-605. (doi:10.1210/er.2005-0020)

16 Gravholt CH \& Weis Naeraa R. Reference values for body proportions and body composition in adult women with UllrichTurner syndrome. American Journal of Medical Genetics $1997 \mathbf{7 2}$ 403-408. (doi:10.1002/(SICI)1096-8628(19971112)72:4<403 ::AID-AJMG6 > 3.0.CO;2-R) 
17 Grundy SM, Cleeman JI \& Daniels SR. Diagnosis and management of the metabolic syndrome: an American Heart Association/ National Heart, Lung, and Blood Institute Scientific Statement. Circulation 2005112 2735-2752. (doi:10.1161/CIRCULATIONAHA.105.169404)

18 Mancia G, Sega R \& Bravi C. Ambulatory blood pressure normality: results from the PAMELA Study. Journal of Hypertension 199513 1377-1390. (doi:10.1097/00004872-199512000-00003)

19 Mancia G, De Backer G, Dominiczak A, Cifkova R, Fagard R, Germano G, Grassi G, Heagerty AM, Kjeldsen SE, Laurent S, Narkiewicz K, Ruilope L, Rynkiewicz A, Schmieder RE, Boudier HA, Zanchetti A, Vahanian A, Camm J, De Caterina R, Dean V, Dickstein K, Filippatos G, Funck-Brentano C, Hellemans I, Kristensen SD, McGregor K, Sechtem U, Silber S, Tendera M, Widimsky P, Zamorano JL, Erdine S, Kiowski W, Agabiti-Rosei E, Ambrosioni E, Lindholm LH, Viigimaa M, Adamopoulos S, Agabiti-Rosei E, Ambrosioni E, Bertomeu V, Clement D, Erdine S, Farsang C, Gaita D, Lip G, Mallion JM, Manolis AJ, Nilsson PM, O’Brien E, Ponikowski P, Redon J, Ruschitzka F, Tamargo J, van Zwieten P, Waeber B, Williams B \& Management of Arterial Hypertension of the European Society of Hypertension; European Society of Cardiology. Guidelines for the Management of Arterial Hypertension: The Task Force for the Management of Arterial Hypertension of the European Society of Hypertension (ESH) and of the European Society of Cardiology (ESC). Journal of Hypertension 200725 1105-1187. (doi:10.1097/HJH.0b013e3281fc975a)

20 Nelder JA. A User's Guide to the Evaluation of Statistical Packages and Systems. International Statistical Review $1974 \mathbf{4 2} 291-298$. (doi:10.2307/1402986)

21 Gravholt $\mathrm{CH}$, Naeraa RW \& Fisker S. Body composition and physical fitness are major determinants of the growth hormoneinsulin-like growth factor axis aberrations in adult Turner's syndrome, with important modulations by treatment with 17 betaestradiol. Journal of Clinical Endocrinology and Metabolism $1997 \mathbf{8 2}$ 2570-2577. (doi:10.1210/jc.82.8.2570)

22 Espeland MA, Stefanick ML \& Kritz-Silverstein D. Effect of postmenopausal hormone therapy on body weight and waist and hip girths. Postmenopausal Estrogen-Progestin Interventions Study Investigators. Journal of Clinical Endocrinology and Metabolism 199782 1549-1556. (doi:10.1210/jc.82.5.1549)

23 Elsheikh M, Bird R \& Casadei B. The effect of hormone replacement therapy on cardiovascular hemodynamics in women with Turner's syndrome. Journal of Clinical Endocrinology and Metabolism 200085 614-618. (doi:10.1210/jc.85.2.614)

24 Brussaard HE, Gevers-Leuven JA \& Frolich M. Short-term oestrogen replacement therapy improves insulin resistance, lipids, and fibrinolysis in postmenopausal women with NIDDM. Diabetologia 199740 843-849. (doi:10.1007/s001250050758)

25 Godsland IF. Oestrogens and insulin secretion. Diabetologia 2005 48 2213-2220. (doi:10.1007/s00125-005-1930-0)

26 Ross JL, Feuillan P, Long LM, Kowal K, Kushner H \& Cutler GB Jr. Lipid abnormalities in Turner syndrome. Journal of Pediatrics 1995 126 242-245. (doi:10.1016/S0022-3476(95)70551-1)

27 Cooley M, Bakalov V \& Bondy CA. Lipid profiles in women with 45,X vs 46,XX primary ovarian failure. Journal of the American Medical Association $20032902127-2128$. (doi:10.1001/jama. 290.16.2127)
28 Walsh BW, Schiff I \& Rosner B. Effects of postmenopausal estrogen replacement on the concentrations and metabolism of plasma lipoproteins. New England Journal of Medicine 1991325 1196-1204. (doi:10.1056/NEJM199110243251702)

29 Sacks FM, Gerhard M \& Walsh BW. Sex hormones, lipoproteins, and vascular reactivity. Current Opinion in Lipidology 19956 161-166. (doi:10.1097/00041433-199506000-00008)

30 Writing Group for the PEPI Trial. Effects of oestrogen or oestrogen/progestin regimens on heart disease risk factors in postmenopausal women. Journal of the American Medical Association 1995273 199-208. (doi:10.1001/jama.273.3.199)

31 Godsland IF. Effects of postmenopausal hormone replacement therapy on lipid, lipoprotein, and apolipoprotein (a) concentrations: analysis of studies published from 1974 to 2000. Fertility and Sterility $2001 \mathbf{7 5}$ 898-915. (doi:10.1016/S0015-0282 (01)01699-5)

32 Kornhauser C, Malacara JM \& Garay ME. The effect of hormone replacement therapy on blood pressure and cardiovascular risk factors in menopausal women with moderate hypertension. Journal of Human Hypertension 199711 405-411. (doi:10. 1038/sj.jhh.1000420)

33 Mortensen KH, Hansen KW, Erlandsen M, Christiansen JS \& Gravholt $\mathrm{CH}$. Ambulatory arterial stiffness index in Turner syndrome: the impact of sex hormone replacement therapy. Hormone Research 200972 184-189. (doi:10.1159/000232495)

34 Cheng KS, Mikhailidis DÀ, Hamilton G \& Seifalian AM. A review of carotid and femoral intima-media thickness as an indicator of the presence of vascular disease and cardiovascular risk factors. Cardiovascular Research 200254 528-538. (doi:10.1016/S00086363(01)00551-X)

35 Ostberg JE, Donald AE, Halcox JP, Storry C, McCarthy C \& Conway GS. Vasculopathy in Turner syndrome: arterial dilatation and intimal thickening without endothelial dysfunction. Journal of Clinical Endocrinology and Metabolism 200590 5161-5166. (doi:10.1210/jc.2005-0677)

36 Ostberg JE, Storry C \& Donald AE. A dose-response study of hormone replacement in young hypogonadal women: effects on intima-media thickness and metabolism. Clinical Endocrinology 200766 557-564. (doi:10.1111/j.1365-2265.2007. 02772.x)

37 Bush DE, Jones CE \& Bass KM. Estrogen replacement reverses endothelial dysfunction in postmenopausal women. American Journal of Medicine $1998 \mathbf{1 0 4} 552-558$. (doi:10.1016/S00029343(98)00117-X)

38 Lieberman EH, Gerhard MD \& Uehata A. Estrogen improves endothelium-dependent, flow-mediated vasodilation in postmenopausal women. Annals of Internal Medicine $1994 \mathbf{1 2 1}$ 936-941.

39 Hodis HN, Mack WJ \& Lobo RA. Estrogen in the prevention of atherosclerosis: a randomized, double-blind, placebo-controlled trial. Annals of Internal Medicine 2001135 939-953.

Received 16 February 2011

Accepted 4 March 2011 